\title{
Effect of false-positive screening mammograms on rescreening in Western Australia
}

Marcus J H Sim Medical Student Siva Prema Siva Medical Student

Intan S Raml Medical Student

Lin Fritschi MB BS, PhD, FAFPHM Professor of Epidemiology

Janette Tresham BSc(Agric), Data Manager

Elizabeth J Wylie MB BS, FRANZCR,

Medical Director, ${ }^{3}$ and Clinical Associate Professor ${ }^{4}$

1 Faculty of Medicine Dentistry and Health Sciences, University of Western Australia Perth, WA.

2 Western Australian Institute for Medical Research, University of Western Australia Perth, WA. 3 BreastScreen WA,
Department of Health, Perth, WA.

4 School of Medicine and Pharmacology, Royal Perth Hospital, University of Western Australia, Perth, WA.

Liz.Wylie@

health.wa.gov.au

MJA 2012; 196: 693-695 doi: 10.5694/mjall.10892 reast cancer is the most common life-threatening cancer in Australian women, with the lifetime risk of breast cancer being one in nine. ${ }^{1}$ BreastScreen Australia provides a screening mammography service to reduce breast cancer mortality and morbidity. $^{2}$ The purpose of a mammographic screening program is to detect breast cancer at an early stage. For a program to be effective, women need to be screened regularly. Worldwide studies on the effect of false-positive screening on rescreening rates are inconsistent and vary by country.

In Western Australia, about 44 in 1000 women screened by BreastScreen WA (BSWA) will have a mammographic abnormality without breast cancer (a false-positive result). ${ }^{2}$ The recall rates for follow-up assessment are less than $10 \%$ for women having their first mammogram and less than $5 \%$ for women having a subsequent examination. These rates meet the BreastScreen Australia National Accreditation Standards. ${ }^{3}$ However, the combined effect of these rates over time may be considerable, with $32.4 \%$ of women who start a breast screening program at the age of 50 years and who participate in 10 consecutive screening rounds (until the age of 69 years) having at least one falsepositive recall. $^{4}$

Adverse psychological outcomes associated with false-positive screens include concern about having breast cancer, anxiety between recall letter and assessment ${ }^{5}$ and anxiety while undergoing further investigative medical procedures. ${ }^{6}$ The literature also indicates that as recall rates increase in a screening service, there is no increase in the cancer detection rates and in screening sensitivity beyond a recall rate of $4.8 \%{ }^{7}$

The anxiety resulting from a falsepositive mammogram may reduce the likelihood of a woman returning for a subsequent screen, as demonstrated by studies in Canada and Europe. ${ }^{8,9}$ However, United States and Irish studies have found that women with false-positive mammogram results are slightly

Abstrac

Objectives: To quantify the effect of previous false-positive mammogram results on rescreening rates in a population of women participating in the BreastScreen WA (BSWA) program.

Design and participants: Retrospective cohort study of women aged 50-69 years who received free screening mammograms at BSWA between 1 January 1995 and 31 December 2007.

Main outcome measures: Percentages of women attending rescreening, and risk ratios for rescreening.

Results: A total of 22396 screening mammograms were falsely reported as positive, and 560333 mammogram screens were reported as normal (negative). Women with a false-positive index mammogram result were less likely than women with a true-negative index mammogram result to attend rescreening at 27 months ( $67.6 \%$ v $70.7 \%$; risk ratio, $0.96 ; P<0.001)$. A reduced rescreening rate was seen in all subgroups of women except Indigenous women. Rescreening rates were affected by the types of assessment done at the recall visit.

Conclusion: Mammographic population screening services should keep their false-positive result rates low, to prevent women from being deterred from screening.

more likely to return for subsequent screening. ${ }^{10,11}$ A meta-analysis that pooled studies from the US, Europe and Canada found that the heterogeneous relationship between false-positive screening and return for rescreening reflects a finding that rescreening rates vary by country. Women in the US were more likely to return for screening, but European and Canadian women were less likely to return for screening. ${ }^{12}$ This was postulated to be due to differences in the duration of the screening interval, false-positive rates, waiting time between recall and assessment and active recruitment of women for routine rescreening. ${ }^{12,13}$ To our knowledge, few studies on this aspect of rescreening have been done in Australia.

BreastScreen Australia has noted falling participation rates over recent years which are not explained by attrition to private mammography. ${ }^{14}$ Our study aimed to quantify the effect of a falsepositive mammogram result on rescreening rates in the BSWA program.

\section{Methods}

\section{Setting}

BSWA started as part of the national breast cancer screening program in 1989. Women aged 50-69 years are the target age group and invitations for a free mammogram are mailed to women identified from the electoral roll. About $55 \%$ of Western Australian women aged 50-69 years are screened through this program every 2 years.

The mammograms are read independently by two radiologists. If there is disagreement between the readers, a third reading is obtained. It is an accreditation standard of BreastScreen Australia that mammogram readers receive regular individual performance data about their recall rates, and each program has performance-monitoring processes in place to help radiologists whose performance falls outside acceptable parameters. ${ }^{3}$ Women with possible lesions detected on screening are invited to assessment clinics for work up of these lesions. Rural women with screen-detected abnormalities have a further mammogram performed in the mobile van and are invited to a metropolitan assessment centre for stage two assessment if there are persistent mammographic abnormalities. Women with screen-detected lesions confirmed to be benign (falsepositive) are returned to routine rescreening. Ninety percent of women are screened biennially and, on the basis of a higher risk of breast cancer, $10 \%$ of women are screened annually. 
1 Comparison of the rescreen rate between women with false-positive index mammogram results and women with true-negative index mammogram results

\begin{tabular}{|c|c|c|c|c|c|c|c|c|}
\hline \multirow[b]{2}{*}{$\begin{array}{l}\text { Screening } \\
\text { group }\end{array}$} & \multicolumn{3}{|c|}{ False-positive index mammograms } & \multicolumn{3}{|c|}{ True-negative index mammograms } & \multirow[b]{2}{*}{$\begin{array}{l}\text { Risk } \\
\text { ratio }\end{array}$} & \multirow[b]{2}{*}{$P^{*}$} \\
\hline & $\begin{array}{l}\text { Number } \\
\text { screened }\end{array}$ & $\begin{array}{l}\text { Number } \\
\text { rescreened }\end{array}$ & $\begin{array}{c}\text { Proportion } \\
\text { rescreened (\%) }\end{array}$ & $\begin{array}{l}\text { Number } \\
\text { screened }\end{array}$ & $\begin{array}{l}\text { Number } \\
\text { rescreened }\end{array}$ & $\begin{array}{c}\text { Proportion } \\
\text { rescreened (\%) }\end{array}$ & & \\
\hline All women & 22396 & 15143 & $67.6 \%$ & 560333 & 1וו1 396 & $70.7 \%$ & 0.96 & $<0.001$ \\
\hline $\begin{array}{l}\text { Women } \\
\text { having first } \\
\text { screens }\end{array}$ & 8273 & 5047 & $61.0 \%$ & 100758 & 62961 & $62.5 \%$ & 0.98 & 0.007 \\
\hline $\begin{array}{l}\text { Women } \\
\text { having } \\
\text { subsequent } \\
\text { screens }\end{array}$ & 14123 & 10096 & $71.5 \%$ & 459575 & 333150 & $72.5 \%$ & 0.99 & 0.008 \\
\hline $\begin{array}{l}\text { Indigenous } \\
\text { women }\end{array}$ & 146 & 90 & $61.6 \%$ & 5907 & 3590 & $60.8 \%$ & 1.01 & 0.83 \\
\hline $\begin{array}{l}\text { Women from } \\
\text { NESB }\end{array}$ & 2584 & 1820 & $70.4 \%$ & 72960 & 52168 & $71.5 \%$ & 0.99 & 0.23 \\
\hline $\begin{array}{l}\text { Metropolitan } \\
\text { women }\end{array}$ & 16433 & 10889 & $66.3 \%$ & 395793 & 276340 & $69.8 \%$ & 0.95 & $<0.001$ \\
\hline Rural women & 5904 & 4129 & $69.9 \%$ & 163122 & 119103 & $73.0 \%$ & 0.96 & $<0.001$ \\
\hline
\end{tabular}

* $P$ calculated from $\chi^{2}$ test. NESB $=$ non-English speaking background.

\section{Study design and population}

This was a retrospective cohort study comprising women aged 50-69 years attending BSWA between 1 January 1995 and 31 December 2007. We excluded women screened annually, women with an abnormal lesion detected on mammogram and subsequently diagnosed with invasive or insitu breast cancer, and women who turned 70 years old before their scheduled rescreen. BSWA collects data for women aged 40-49 years and women aged over 70 years, but these groups were not included in the study as the program does not actively recruit participants outside the target age group.

The first screening mammogram obtained by women at BSWA during the study period was considered the index mammogram. Rescreening invitations were mailed 24 months after the index mammogram. Women who did not attend a mammogram screening within 27 months of their index mammogram were recorded as "nonattended", and women who attended within 27 months were recorded as "attended".

The rescreen mammogram was considered the new index mammogram for the next 27-month follow-up period. Women recorded as non-attended and who subsequently rejoined the program during the study period had their later mammogram taken as the new index mammogram. When a woman presented to BSWA for her initial examination, it was classified as a first-time screen. If the woman returned after that initial screen (whether before or after the 27-month period) it was described as a subsequent screen. This subsequent screen became the new index screen, so some women were counted multiple times within the 13-year study period.

Women complete a questionnaire at the time of screening, which collects information on Aboriginal and Torres Strait Islander descent and non-English speaking background. We obtained data about whether the index mammograms had occurred at metropolitan or rural services from the BSWA database. Diagnostic investigations done at recall visits were classified as further mammography; ultrasound only; fine-needle aspirate or core biopsy; and diagnostic open biopsy.

Our main interest was in comparing the rescreen rate between those whose index mammograms were negative and those whose index mammograms were positive and not diagnosed with breast cancer (false-positive). $\chi^{2}$ tests were used to determine the statistical significance of the difference between the rescreen proportions. We repeated the comparison, stratifying for:

- whether the index screen was an initial or a subsequent screen

- if the woman was of Aboriginal or Torres Strait Islander descent

- if the woman had a non-English speaking background

- whether the index screen was performed by a metropolitan or a rural screening service.

Our secondary objective was to examine the rescreening rates according to the type of investigation performed at the recall visit.

All women screened at BSWA signed a consent form at each screening episode, permitting their de-identified screening and assessment data to be used for research and publication.

\section{Results}

Between 1 January 1995 and 31 December 2007, 22396 women screened for breast cancer had a false-positive result, and 560333 women screened had a true-negative result (Box 1). Of the women with a false-positive result, 15143 returned for rescreening within 27 months $(67.6 \%)$, and of women with a true-negative result, 396111 were rescreened within 27 months (70.7\%). Overall, women with a false-positive index mammogram result were less likely to attend for rescreening at 27 months (risk ratio, 0.96; $P<0.001$ ).

Women who had participated in the BSWA program before (women having subsequent screens) were more likely to return for rescreening compared with women having first screens. This outcome applied to women who had a false-positive index screen and women who had a true-negative screen (Box 1). Indigenous women were slightly more likely to return for rescreening after a falsepositive screen compared with Indigenous women after a true-negative screen. This finding did not reach statistical significance. Women from non-English speaking backgrounds were less likely to attend for rescreening following a false-positive screen compared than those who had a truenegative screen, but this finding did not reach statistical significance.

Women having their mammograms at rural centres were more likely to return for a rescreen at 27 months, compared with women having their mammograms at metropolitan centres. This was the case for the true-negative and false-positive results groups.

Following a false-positive result, rescreening attendance was affected by the type of assessment (Box 2). Women who had an invasive procedure (fineneedle aspirate or biopsy) were less likely to participate in rescreening at 27 months than those who had further mammography or ultrasound. 


\section{Discussion}

Our results show that women with a false-positive screening mammogram result are deterred, to a small extent, from participation in future screenings. These findings concur with studies reported from Europe and Canada and are possibly due to similarities in structure and protocols between the national screening programs. ${ }^{8,9,12}$ The decrease in participation in rescreening $(3.1 \%)$ is small but statistically significant, and when taken in the context of a program that screens over 100000 women a year, equates to about 150 women annually deterred from screening and not receiving the benefits of early detection.

Previous participation in the BSWA program is a strong marker for likelihood of attending a rescreen, compared with no previous participation. This may reflect higher levels of familiarity and commitment to participation in the screening process of women who have previously participated. ${ }^{11}$ Living in a rural area appears to provide a small benefit to the likelihood of attending rescreening, which may be related to the limited times that mobile vans are stationed in rural towns, motivating women to use the screening opportunity.

Recent data indicate that recall rates are rising for breast screening services across Australia, accompanied by falling participation rates. ${ }^{2,15}$ To reduce false-positive recall rates, it is important for a screening service to ensure that regular performance feedback is given to radiologists who read the mammograms. Another strategy to reduce recall rates is to make previous mammograms available at the time of reporting, so that only new mammographic changes are assessed. ${ }^{16}$

A positive first-time screening experience, in which embarrassment and discomfort are well managed, and patients are satisfied with the communication and information provided during the screening process, has been shown to decrease the likelihood of adverse psychological effects of a false-positive recall and strongly influences a woman's decision to rescreen. ${ }^{2,17}$

Our study was based on a statewide screening program that invites all women between the ages of 50 and 69 years to participate, and was not limited to a highly selected cohort of women. Data were collected in a standardised way and have been audited regularly, ${ }^{15}$ with observed rescreening rates, not self-reported rescreening rates, as the end point of the study, thus reducing misclassification.

A limitation of this study was the use of compiled data, which precluded statistical adjustment for multiple variables. The study population also includes women who did not attend rescreening because they had moved interstate or overseas, or who had their subsequent screen performed privately. We assumed that these groups comprised a small minority of the false-positive and true-negative result cohorts. We used data from a 27-month follow-up period, so some women would have had more than one index mammogram in the study period, thus, the data are not strictly statistically independent. This would not affect the point estimates, but the confidence intervals would be slightly wider.

Women with false-positive screening mammograms are less likely to participate in subsequent screening rounds than those with a normal index mammogram at BSWA. High false-positive recall rates in a screening program may result in some women being deterred from screening and from receiving the benefits of early detection.

Acknowledgements: We thank Sally Burrows for statistical assistance and Rose Bryant for editing assistance.

Competing interests: No relevant disclosures.

Received 13 Jul 2011, accepted 23 Jan 2012.

1 Australian Bureau of Statistics. Cancer in Australia: a snapshot, 2004-05. Canberra: ABS, 2006. http://www.abs.gov.au/ausstats/abs@.nst/mf/ 4822.0.55.001 (accessed Nov 2011).

2 Australian Institute of Health and Welfare. BreastScreen Australia monitoring report 20052006. Canberra: AlHW, 2009. (AlHW Cat. No. CAN 44.) http://www.aihw.gov.au/publicationdetail/?id=6442468276 (accessed Apr 2012).

3 National Quality Management Committee of BreastScreen Âustrália. BreastScreen Âustralia national accreditation standards: quality improvement program. Canberra: BreastScreen Australia, 2008. http://www.cancerscreening. gov.au/internet/screening/publishing.nsf/ Content/br-accreditation/\$File/standards.pdf (accessed Apr 2012).

4 Castells X, Molins E, Macià F. Cumulative false positive recall rate and association with participant related factors in a population based breast cancer screening programme. J Epidemiol Community Health 2006; 60: 316-321.
2 Type of assessment performed at recall visit for women with false-positive index mammogram results

\begin{tabular}{lccc}
$\begin{array}{l}\text { Assessment } \\
\text { at recall visit }\end{array}$ & $\begin{array}{c}\text { Women with } \\
\text { false-positive } \\
\text { index } \\
\text { mammograms }\end{array}$ & $\begin{array}{c}\text { Women } \\
\text { rescreened }\end{array}$ & $\begin{array}{c}\text { Proportion } \\
\text { of women } \\
\text { rescreened } \\
(95 \% \mathrm{Cl})\end{array}$ \\
\hline $\begin{array}{l}\text { Further } \\
\text { mammography }\end{array}$ & 10746 & 7687 & $\begin{array}{c}71.5 \% \\
(71.48-71.52)\end{array}$ \\
$\begin{array}{l}\text { Ultrasound } \\
\text { only }\end{array}$ & 5238 & 3466 & $\begin{array}{c}66.2 \% \\
(66.14-66.20)\end{array}$ \\
$\begin{array}{l}\text { Fine-needle } \\
\text { aspirate or } \\
\text { core biopsy }\end{array}$ & 5233 & 3357 & $\begin{array}{c}64.1 \% \\
\text { Diagnostic } \\
\text { open biopsy }\end{array}$ \\
\hline
\end{tabular}

5 Brett J, Austoker J, Ong G. Do women who undergo further investigation for breast screening suffer adverse psychological consequences? A multi-centre follow-up study comparing different breast screening result groups five months after their last breast screening appointment. J Public Health Med 1998 20: 396-403.

6 Brett J, Bankhead C, Henderson B, et al. The psychological impact of mammographic screening. A systematic review. Psychooncology 2005; 14: 917-938.

7 Feig SA. Adverse effects of screening mammography. Radiol Clin North Am 2004; 42: 807-819.

8 Chiarelli AM, Moravan V, Halapy E, et al. Falsepositive result and reattendance in the Ontario Breast Screening Program. J Med Screen 2003; 10:129-133.

9 McCann J, Stockton D, Godward S. Impact of falsepositive mammography on subsequent screening attendance and risk of cancer. Breast Cancer Res 2002; 4: R11.

10 Burman ML, Taplin SH, Herta DF, Elmore JG. Effect of false-positive mammograms on interval breast cancer screening in a health maintenance organization. Ann Intern Med 1999; 131: 1-6.

11 Fitzpatrick P, Fleming P, O'Neil S, et al. Falsepositive mammographic screening: factors influencing re-attendance over a decade of screening. J Med Screen 2011; 18: 30-33.

12 Brewer NT, Salz T, Lillie SE. Systematic review: the long-term effects of false-positive mammograms. Ann Intern Med 2007; 146: 502-510.

13 Lindfors KK, O'Connor J, Parker RA. False-positive screening mammograms: effect of immediate versus later work-up on patient stress. Radiology 2001; 218: 247-253.

14 Quaine J, Barber G, Delaney J, et al; BreastScreen Australia Evaluation Advisory Committee. Screening Monograph No. 1/2009 - evaluation final report. Canberra: Commonwealth of Australia, 2009. http://www.health.gov.au/ internet/screening/publishing.nsf/Content/ br-evaluation-lp (accessed Nov 2011).

15 Australian Institute of Health and Welfare. BreastScreen Australia monitoring report 20062007 and 2007-2008: supplementary data tables. Canberra: AlHW, 2010. (AlHW Cat. No. CAN 52; Cancer Series No. 56.) http:// www.aihw.gov.au/publication-detail/? id=6442468383 (accessed Apr 2012).

16 Thurfjell MG, Vitak B, Azavedo E, et al. Effect on sensitivity and specificity of mammography screening with or without comparison of old mammograms. Acta Radiol 2000; 41: 52-56.

17 Austoker J, Ong G. Written information needs of women who are recalled for further investigation of breast screening: results of a multicentre study. J Med Screen 1994; 1: 238-244. 